\title{
Ice ridging and ice drift in southern Gulf of St Lawrence, Canada, during winter storms
}

\author{
S.J. PRINSENBERG, A. VAN DER BAAREN, I.K. PETERSON \\ Bedford Institute of Oceanography, 1 Challenger Drive, PO Box 1006, Dartmouth, Nova Scotia B2Y 4A2, Canada \\ E-mail: prinsenbergs@mar.dfo-mpo.gc.ca
}

\begin{abstract}
During February and March 2004, satellite-tracked ice beacons and helicopter-borne sensors collected ice-drift and ice-thickness data from the southern Gulf of St Lawrence, Canada, to study the region's ice-thickness evolution and ice-drift behavior in response to winter storms. Three northeasterly storms passed through the area during the observation period, pushing the pack ice against the north shore of Prince Edward Island. The resulting severe ice deformation caused major changes in the ice-thickness distribution of two pack-ice areas tracked by ice beacons that survived the storms. The ice drift ranged from $1.4 \%$ to $2.9 \%$ of the wind speed during free ice-drift conditions, decreasing to $0 \%$ when the pack ice compacted against the shoreline. Most of the thinner ice deformed first, increasing the mean ice thickness over 6-8 km line sections around the beacons from 0.6 and $0.3 \mathrm{~m}$ before the storms to 1.9 and $2.0 \mathrm{~m}$ after the storms. The ice-thickness increases can be accounted for by the reduced pack-ice area due to ice ridging. Over the next 4 weeks, deformation continued and the mean ice thickness around the beacons increased to $2.8 \mathrm{~m}$, well in excess of the maximum undeformed possible ice growth of $65 \mathrm{~cm}$. Ice charts captured the ice thickness of undeformed and composite ice floes but did not capture the ice volume in ice-rubble fields.
\end{abstract}

\section{INTRODUCTION}

Ice mass balance of sea ice is one of the key parameters in climate studies and is one of the main foci of ice-ocean models that simulate the past and future changes in the global cryosphere. While spatial extent of sea ice has been accurately estimated from satellite remote-sensed imagery, ice-thickness distributions are difficult to determine directly from satellite imagery. Ice mass-balance estimates have relied mainly on ice-thickness data from upward-looking sonar data collected by submarines (Wadhams and Davis, 2000; Yu and others 2004) and by moorings (Melling and Riedel, 2004; Melling and others, 2005). Within the seasonal ice mass balance, one has to account for both thermodynamic and dynamic effects on the ice-thickness evolution. Data on thermodynamic ice growth and decay for the Arctic pack ice are available through satellite-tracked ice beacons (Richter-Menge and others, 2006). Data on tracking and resampling a specific Arctic pack-ice region to determine dynamic ice growth are not available, although attempts are being made with helicopter-borne sensors and satellite-tracked ice beacons (Haas and others, 2006). For the sub-Arctic, one such dataset is available from the Gulf of St Lawrence, Canada, and is presented in this paper. The survey was run during February and March 2004 out of Charlottetown, Prince Edward Island (PEl; Fig. 1), using Canadian Coast Guard BO105 helicopters.

\section{INSTRUMENTATION}

Sea-ice thickness and surface ice roughness were measured with a helicopter-borne electromagnetic (EM) system, called 'IcePic', which can be used to obtain either spot samples of ice thickness by soft-landing on the ice, or ice-thickness profiles by flying at low altitude over the pack ice. The EM sensor provides the distance to the surface of the sea water, while a laser altimeter provides the distance to the surface of the ice (or snow if present); together they provide the snowplus-ice thickness (Prinsenberg and others, 2002). The laser altimeter data are also used to provide ice surface roughness after the slow-varying helicopter height is removed (Hibler, 1972). The EM footprint size (or spatial area over which it averages) is dependent on the altitude of the sensor above the sea-water surface and is 9-12 $\mathrm{m}$ for the IcePic over $1 \mathrm{~m}$ thick ice flying at $3 \mathrm{~m}$ altitude (Kovacs and others, 1995). Several studies have successfully validated snow-plus-ice thickness measurements from IcePic by comparing them with ice and snow thicknesses measured at holes drilled through the ice (Peterson and others, 2003).

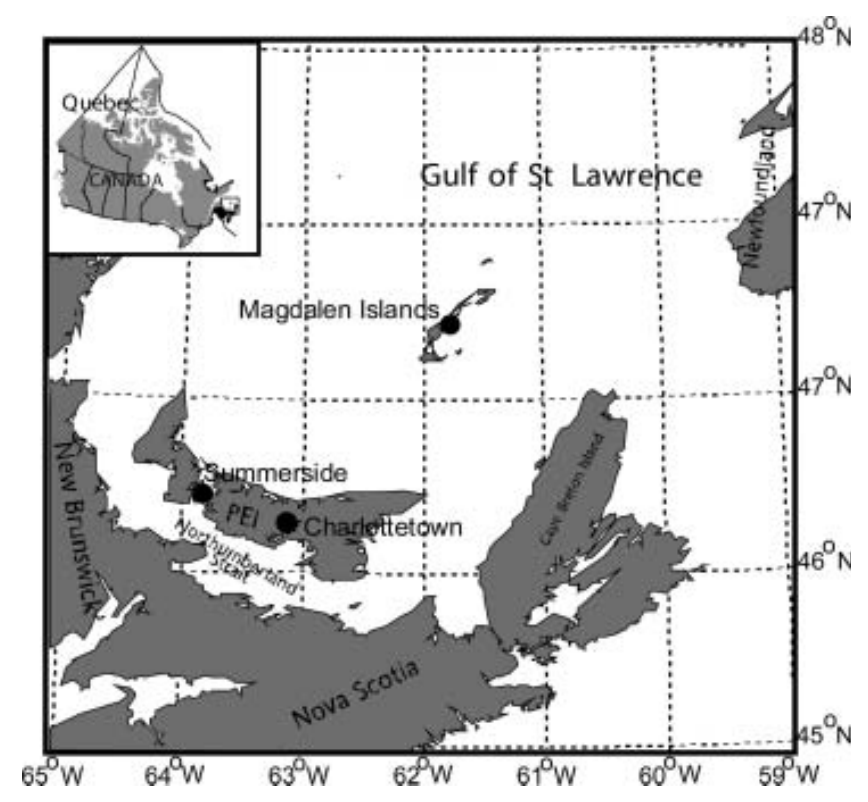

Fig. 1. Map showing Prince Edward Island (PEI) in the southern Gulf of St Lawrence. 


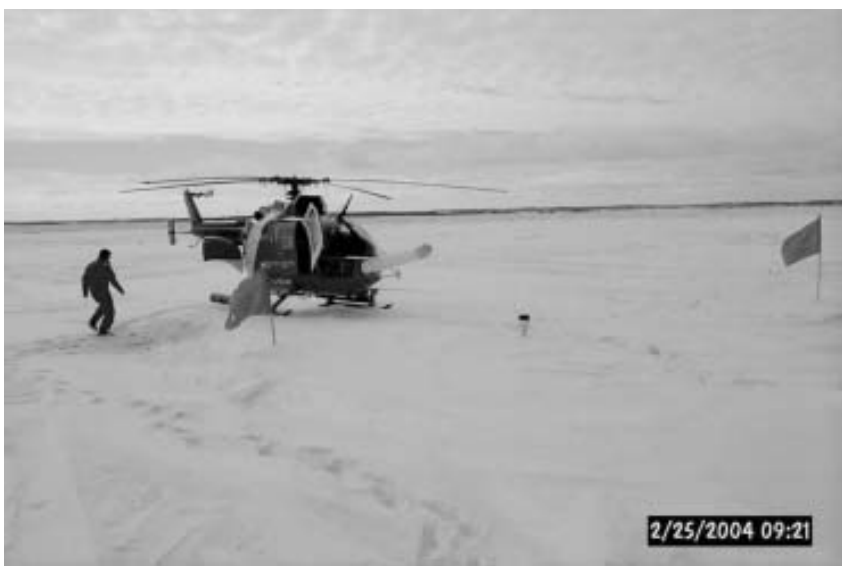

Fig. 2. Canadian Coast Guard helicopter on the Gulf of St Lawrence pack directly behind ice beacon 26370 . The EM/laser system can be seen fixed-mounted to the front of the helicopter.

Satellite-tracked ice beacons placed on the ice are used to relocate the pack-ice region being sampled and to correct the location of the EM data overlain on imagery for ice drift. A third use for the beacon data is to study the response of the pack ice to wind forcing. The beacons used in the survey were manufactured by Seimac Ltd of Dartmouth, Nova Scotia. The beacon's electronic components are sealed in a fiber-glass shell and deployed such that the bottom section of the beacon sits in a shallow ice-auger hole. This keeps the battery pack (bottom part of beacon) as warm as possible and extends its battery life. The beacons are equipped with global positioning system (GPS) sensors that capture the beacon location on the hour. They store internally the most recent 8 hourly locations and transit these to the System Argos satellites as they pass overhead. The Argos system (on US National Oceanic and Atmospheric Administration (NOAA) satellites) receives the most recent 8 hourly data, from which a regular hourly time series can be constructed. Figure 2 shows beacon 23670 along with the EM IcePic sensor mounted on the front of the BO105 helicopter. The picture was taken on 25 February, when the beacon's location was revisited after the first two storms. The storms also increased the snow depths on the ice by $10-15 \mathrm{~cm}$.

\section{OBSERVATIONS}

An Envisat synthetic aperture radar (SAR) image from 18 February, covering a $50 \mathrm{~km}$ by $50 \mathrm{~km}$ area north of PEI, is shown in Figure 3. Beacon 26370 (open square) was deployed on the $65 \mathrm{~cm}$ thick composite ice floe $(5 \mathrm{~km} \times 8 \mathrm{~km})$

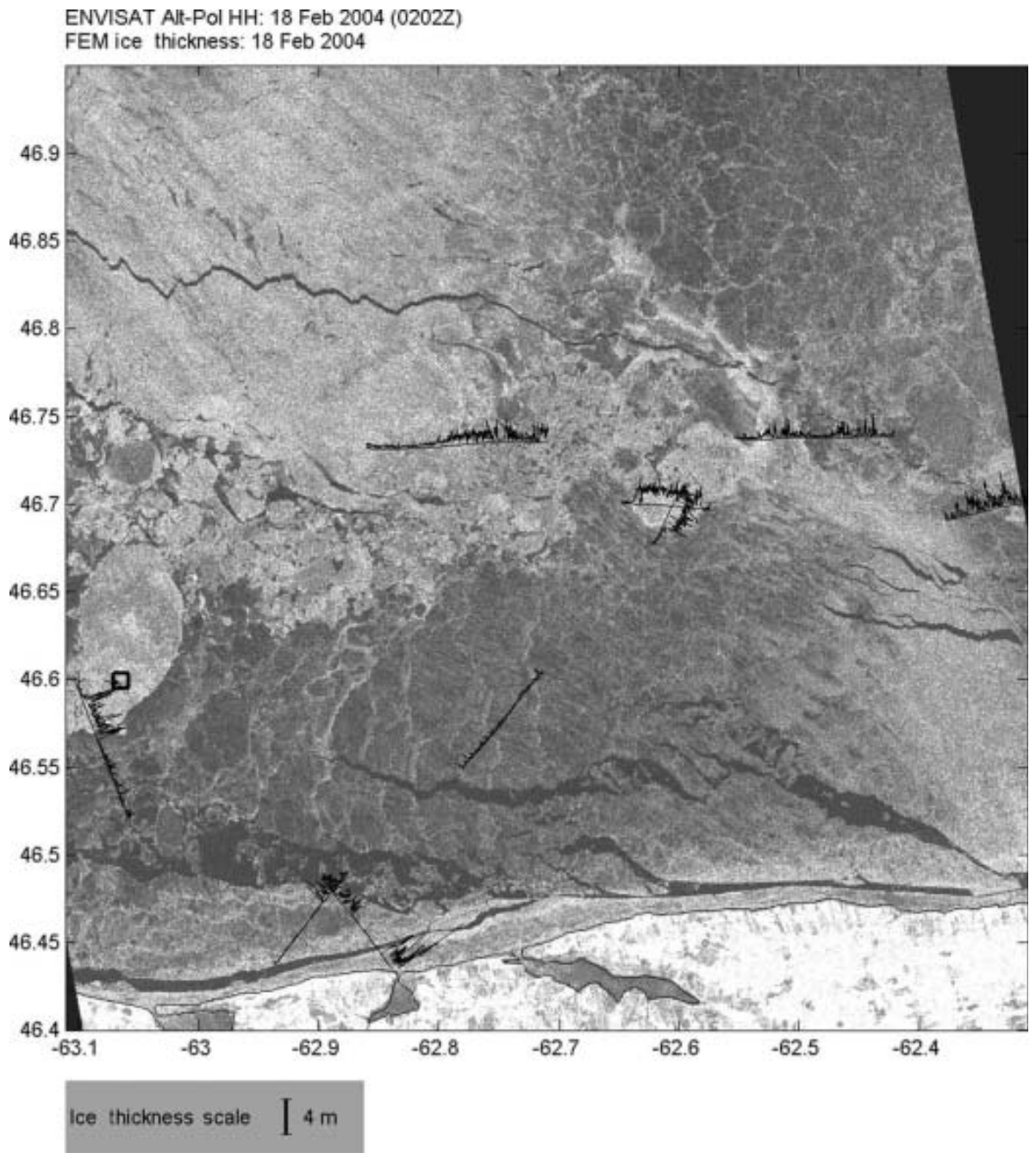

Fig. 3. Satellite Envisat SAR image showing the ice conditions of a $50 \mathrm{~km}$ by $50 \mathrm{~km}$ area north of PEI overlain with the EM ice-thickness data of 18 February 2004. (C) European Space Agency 2004, Envisat AO project 178.) 


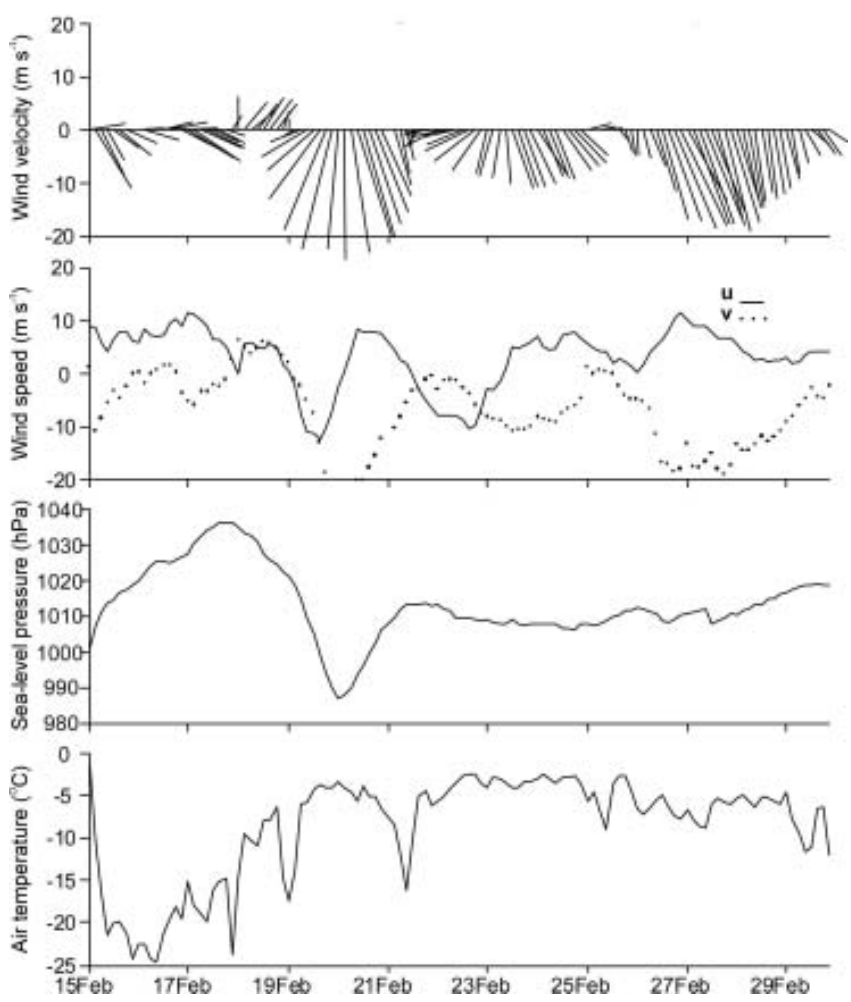

Fig. 4. Two-week time series of 3 hourly meteorological data for southern Gulf of St Lawrence, gridpoint at $47^{\circ} \mathrm{N}, 63^{\circ} \mathrm{W}$.

that was located at the left edge of the image at $46.6^{\circ} \mathrm{N}$. Beacon 26386 was deployed on the uniform $30 \mathrm{~cm}$ thick pack-ice area (grey-colored area) at $46.7^{\circ} \mathrm{N}$, just off the right edge of the image at $62.1^{\circ} \mathrm{W}$. The image is overlain with the EM ice-thickness data collected on 18 February, whose locations were corrected to the image observation time for ice drift using the beacon drift data. The north shore of PEI is at the bottom of the image and separated from the landfast ice by the thin black-marked shoreline. The thin pack ice (grey in image) along the coast, along with some thicker landfast ice (bright in image), has broken away from the coast. In general, the thicker pack ice is represented by the bright areas of this image and found in the top-left part of the image. Offshore leads are present (dark grey areas) indicating that the pack ice was diverging on 18 February. The thinner ice (grey) is mostly found in the bottom and topright corner of the image.

Three- and six-hourly meteorological data were available for the Gulf of St Lawrence region from regional prognostic numerical forecast models run at the Canadian Meteorological Centre, Montreal. The meteorological data were linearly interpolated in time to hourly values and then from the grid fields to beacon positions. Figure 4 shows the wind, pressure and temperature conditions for the last 2 weeks of February 2004 at a gridpoint north of $\mathrm{PEI}$ at $47^{\circ} \mathrm{N}, 63^{\circ} \mathrm{W}$.

The major northeasterly storm of 19-20 February is clearly visible in pressure and wind plots. The air temperature increased as the air mass driven by a low atmospheric depression actually picks up moisture and heat from the open North Atlantic Ocean. In contrast, northwesterly winds (16-17 February) associated with atmospheric highs occur during cold spells when an Arctic air mass enters the region from northern Canada. The 19-20 February storm was followed by two other northerly wind events on 23 and
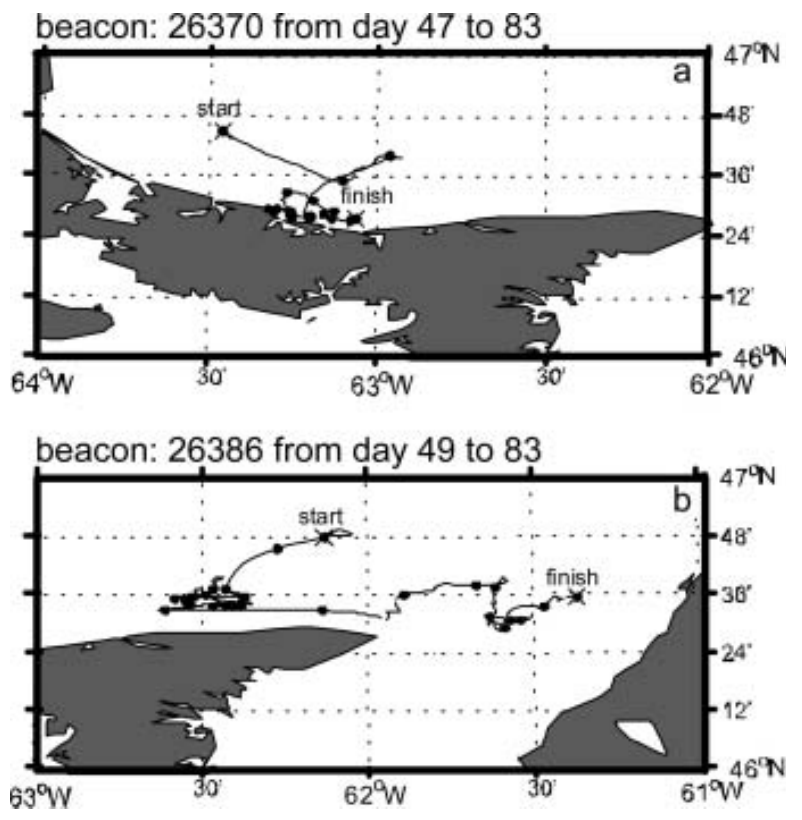

Fig. 5. Trajectories of ice beacon 26370 from 16 February to 23 March 2004, and beacon 26386 from 18 February to 23 March 2004.

28 February providing onshore winds that compressed the pack for 10 days against the north shore of PEI. After 1 March the directions of the weaker winds altered regularly between southerlies and northerlies, causing alternating pack-ice compression and decompression events.

Beacon 26370 was deployed on 16 February on a $65 \mathrm{~cm}$ thick composite ice floe, and beacon 26386 on 18 February on a small $10 \mathrm{~m} \times 10 \mathrm{~m}$ rafted floe surrounded by miles of $30 \mathrm{~cm}$ thick grey ice. The small rafted floe was $60 \mathrm{~cm}$ thick, twice as thick as the surrounding pack ice. It was the thickest ice in this part of the pack ice and one of the reasons the beacon survived the ice deformation that occurred around it. Three other beacons were also deployed on the pack ice, with the intent to follow their region's ice-thickness evolution, but they did not survive the pack-ice deformation caused by the 19-20 February storm. Beacons 26370 and 26386 were recovered from the pack ice on 23 March and provided over 800 hourly position data points. The trajectories of the beacons covering 35 and 37 days are shown in Figure 5.

\section{ICE-DRIFT ANALYSIS}

Beacon 26370 first moved 1 day $30 \mathrm{~km}$ southeast before moving 1 day $20 \mathrm{~km}$ northeast away from the shore. By 18 February both beacons were on the ice and moved 30$40 \mathrm{~km}$ southwest towards the PEI shore due to the northeasterly storm of 19-20 February. Under northerly winds both beacons remained within the ridged pack ice compressed against the PEI shore until 1 March. After 1 March, interchanging southerly and northwesterly winds moved the beacons (and pack ice) offshore and onshore and steadily eastwards, the direction of the mean ice drift.

In addition to tracking specific pack-ice areas to study ice-thickness evolution, the beacon data were used to study the response of pack ice to wind forcing. The data documented how the ice motion stopped once the particular pack-ice region finished its ridging and became trapped 

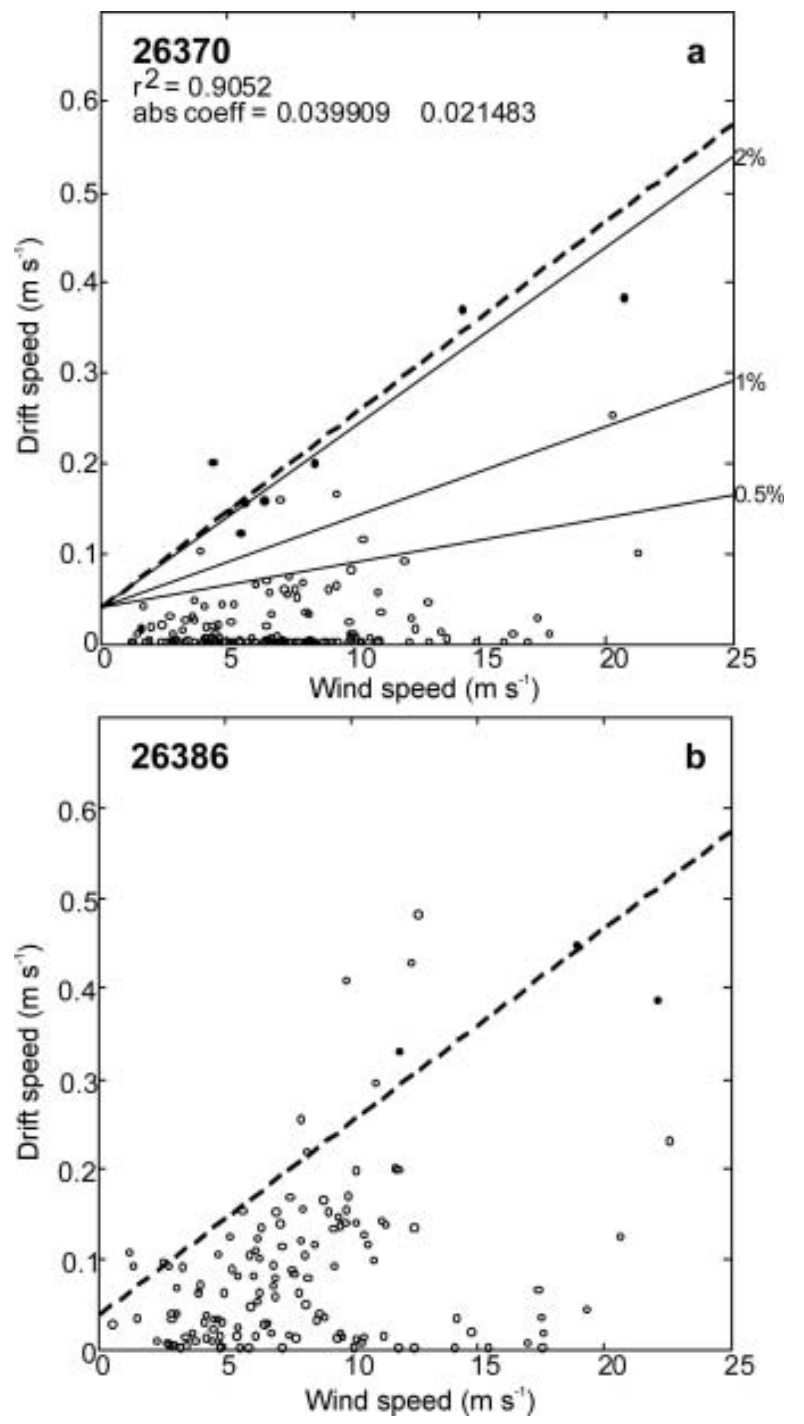

Fig. 6. Scatter plots of observed 6 hourly drift speed vs modeled wind speed for both beacons. Solid dots are observations before 20 February, and open circles after 20 February.

within the temporary landfast ice along the shore of PEI. Regression analysis was first done between ice drift and the modeled wind up to 20 February, the free ice-drift period (a and $\mathrm{b}$ in Table 1 ).

For beacon 26370, the correlation-squared coefficient $\left(R^{2}\right)$ between the two velocity vectors was 0.88 , the mean turning angle of the ice drift to the right of the wind was $37^{\circ}$, the average ratio of the magnitudes of ice to wind (gain) was $3.3 \%$ and there was a zero-wind ice-drift speed of $6.3 \mathrm{~cm} \mathrm{~s}^{-1}$ (Table 1). For the shorter record of beacon 26386, the correlation coefficient $R^{2}$ was 0.87 , the mean turning angle was $58^{\circ}$, the gain was $2.9 \%$ and the zero-wind ice-drift speed was $5.7 \mathrm{~cm} \mathrm{~s}^{-1}$. After 4 March, the $R^{2}$ was low even though the beacons (especially beacon 26386) appeared to be drifting freely again without coastal interference. The regression values before 20 February were comparable to free ice-drift conditions (Peterson and others, 1998), but the variations about the means were large, and one wonders about the accuracy of the modeled winds, as well as the tidal current effects on the wind-drift analysis.

To eliminate some of the tidal current effects, the regression was redone with 6 hourly ice-drift data that were run through a 12 hourly tidal eliminating Cartwright filter
Table 1. Regression results using hourly data for (a) before 20 February and (b) after 4 March, and using 6 hourly, tidal filtered data for (c) before 20 February and (d) after 4 March. Bold values have $R^{2}$ greater than 0.5

\begin{tabular}{ccccccc}
\hline & $\begin{array}{c}\text { Beacon } \\
\text { No. }\end{array}$ & $R^{2}$ & $\Phi$ & Gain & Speed & $\begin{array}{c}\text { Number } \\
\text { of points }\end{array}$ \\
& & & 0 & $\%$ & $\mathrm{~cm} \mathrm{~s}^{-1}$ & \\
\hline a & 26370 & $\mathbf{0 . 8 8}$ & $\mathbf{3 7 . 4}$ & $\mathbf{3 . 3}$ & $\mathbf{6 . 3}$ & $\mathbf{7 2}$ \\
& 26386 & $\mathbf{0 . 8 7}$ & $\mathbf{5 8 . 0}$ & $\mathbf{2 . 9}$ & $\mathbf{5 . 7}$ & $\mathbf{3 0}$ \\
$\mathrm{b}$ & 26370 & 0.21 & 86.4 & 0.4 & 1.1 & 474 \\
& 26386 & 0.42 & 65.2 & 1.6 & 4.7 & 474 \\
$\mathrm{c}$ & 26370 & $\mathbf{0 . 9 1}$ & $\mathbf{3 4 . 2}$ & $\mathbf{2 . 1}$ & $\mathbf{4 . 0}$ & $\mathbf{9}$ \\
& 26386 & - & - & - & - & - \\
$\mathrm{d}$ & 26370 & 0.38 & 67.0 & 0.4 & 1.0 & 73 \\
& 26386 & $\mathbf{0 . 6 7}$ & $\mathbf{4 1 . 2}$ & $\mathbf{1 . 4}$ & $\mathbf{4 . 5}$ & $\mathbf{7 6}$ \\
\hline
\end{tabular}

(c and d in Table 1). Before 20 February, the correlation $\left(R^{2}\right)$ for beacon 26370 increased to 0.91 , and the gain reduced to $2.1 \%$ from $3.3 \%$. The 6 hourly dataset of beacon 26386 was too short for analysis. After 4 March, the $R^{2}$ of beacon 26386 increased to 0.67 and had a gain of $1.4 \%$ and a turning angle of $41^{\circ}$.

Figure 6 shows the scatter plots of observed filtered 6 hourly ice drifts vs 6 hourly modeled winds. The solid lines represent constant gain lines using the zero-wind speed offset of $4.0 \mathrm{~cm} \mathrm{~s}^{-1}$ as observed for the area by beacon 26370 . The dashed lines represent the gain of $2.1 \%$ derived by regression analysis of beacon 26370 data before 20 February (Table 1) and represent free ice-drift conditions. The solid circles represent observations before 20 February, while open circles represent the remaining data after 20 February. Most of the open circles for beacon 26370 fell below the free-drift dashed line as the ice drift was restricted by the coastline. As with beacon 26386, most of the data points after 20 February fell below the dashed regression line. However, towards the end of the time series, the pack ice being tracked by beacon 26386 approached free-drift conditions as shown in the trajectory (Fig. 5) and also in the regression analysis results (Table 1).

\section{ICE-THICKNESS EVOLUTION}

Ice-thickness data were collected for the pack-ice regions being tracked by the two ice beacons. Figure 7 shows the spatial ice-thickness profile across the $65 \mathrm{~cm}$ thick composite ice floe on which beacon 26370 was deployed (see Fig. 3). The ice chart of 17 February correctly showed that the region consisted of $3 / 10$ thin first-year ice $(30-70 \mathrm{~cm})$ and $7 / 10$ grey-white ice $(10-30 \mathrm{~cm})$. The line profile shows that along an east-west direction, the floe at the latitude of the beacon was $6 \mathrm{~km}$ wide and surrounded by thin 10 $15 \mathrm{~cm}$ thick ice as indicated on the ice chart. The composite ice floe consisted of $65 \mathrm{~cm}$ thick level-ice sections surrounded by ridges up to $3 \mathrm{~m}$ thick. The thinner ice surrounding the floe occupied the $15 \mathrm{~km}$ area between the floe and the landfast ice along PEI (see Fig. 3). The ice chart indicated that this region was covered with $4 / 10$ grey ice $(10-15 \mathrm{~cm})$ and $6 / 10$ new ice $(<10 \mathrm{~cm})$. Although this area of thin ice probably grew in thickness between 17 and 19 February, it was completely ridged during the 1920 February storm. 


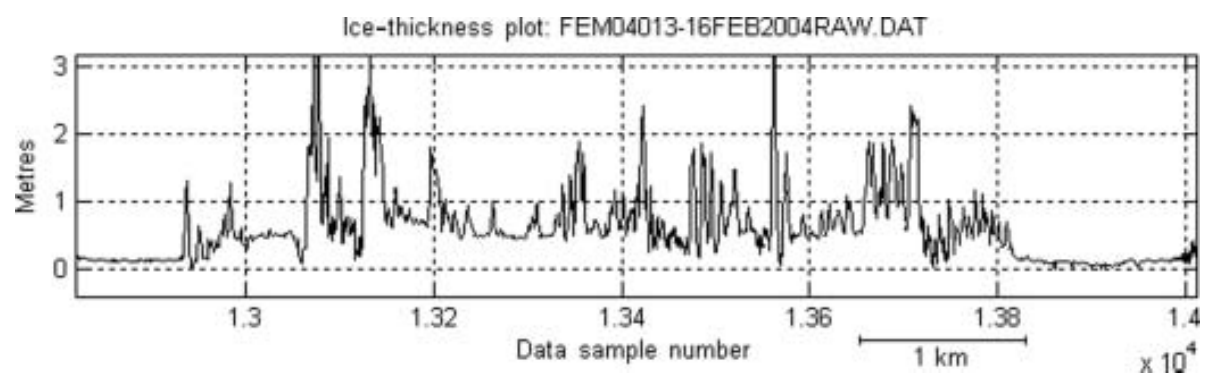

Fig. 7. Ice-thickness line profile from 16 February 2004 of a 7 km east-west line section across the composite ice floe on which beacon 26370 was deployed.

The ice-thickness distribution around beacon 26386 shows that the floe was one of several small rafted floes within a large area of $30 \mathrm{~cm}$ thick ice (Fig. 8). The $6 \mathrm{~km}$ line profile shows the predominant $20-30 \mathrm{~cm}$ thick ice, some small rafted floes $50-60 \mathrm{~cm}$ thick and ridges up to $2 \mathrm{~m}$ thick. On 18 February, thin ice existed over the $30 \mathrm{~km}$ area between the beacon location and PEI. The ice chart of 18 February indicated that this area consisted of 4/10 grey ice $(10-15 \mathrm{~cm})$ and $6 / 10$ new ice $(<10 \mathrm{~cm})$, thinner than what the EM sensor observed and auger holes (three) just off the rafted floe indicated.

The pack-ice areas tracked by the two beacons were revisited after the first two storms on 24 and 25 February and again a month later on 25 March. Ice-thickness data, similar to data shown in Figures 7 and 8, were obtained along three parallel lines $50 \mathrm{~m}$ apart. The data of the three lines were combined to derive ice-thickness histograms (Figs 9 and 10). Only one profile line was available for 18 February from the pack ice where beacon 26386 was deployed, as the storm was approaching faster than originally forecast. Before the 19-20 February storm, the ice-thickness histogram around beacon 26370 (Fig. 9) clearly shows a peak at around 60$70 \mathrm{~cm}$, the mean ice thickness of the composite ice floe the beacon was placed on. A second peak at $10-20 \mathrm{~cm}$ represents the thin ice surrounding the floe. Open water was encountered for about $10 \%$ of the distance covered by the three lines, and is represented by the first bar of the histogram. This indicates that leads were present as the pack ice was diverging as seen in the SAR image (Fig. 3).

After the first two storms, the histogram on 24 February still showed a peak around $70-80 \mathrm{~cm}$, the thickness of the original floe plus a $10-15 \mathrm{~cm}$ increase in snow depth. The beacon was now $1.0 \mathrm{~km}$ from the landfast shear ridge, indicating that the thin mobile pack-ice area was reduced to $1 / 15$. Most of the thin ice was ridged to thickness of $4-5 \mathrm{~m}$, and the mean ice thickness had increased from $66 \mathrm{~cm}$ to $200 \mathrm{~cm}$, accounting for ridging of thin ice $(15 \times(10-15 \mathrm{~cm}))$. The ice chart of 25 February correctly indicated the small floe sizes $(20-100 \mathrm{~m})$ but did not indicate any ice thicker than medium first-year ice $(70-120 \mathrm{~cm})$ and did not capture any of the observed ice-rubble fields that were present along the three flight-lines. By 23 March, 4 weeks later, the ridging had further deformed the ice around the beacon, with the bulk of the ice now ridged and piled up to depths of $3.5 \mathrm{~m}$. The original ice-thickness peak of $60-80 \mathrm{~cm}$ seen in histograms of 16 and 24 February is not recognizable. Due to rubble formation, the mean thickness in the area has increased to $2.8 \mathrm{~m}$. The ice chart of 23 March still correctly indicates small floes $(20-100 \mathrm{~m})$ and an increase in ice thickness, with $4 / 10$ of the ice greater than $120 \mathrm{~cm}$ thick and $4 / 10$ of the ice $70-120 \mathrm{~cm}$ thick. It still does not capture the much larger fraction of thick ice $(3.5-4.5 \mathrm{~m})$ within the icerubble fields.

The evolution of the thin $20-30 \mathrm{~cm}$ ice around beacon 26386 undergoes a similar transformation (Fig. 10). The peak in the histogram after the storm (25 February) is still present at $30-40 \mathrm{~cm}$, increased by the larger snow depth, but most of the original flat ice had been deformed into ice rubble with thicknesses up to 4 and $5 \mathrm{~m}$. The $25 \mathrm{~km}$ area between the beacon and the shoreline was reduced to $5 \mathrm{~km}$ and accounted for the increase in mean ice thickness from $34 \mathrm{~cm}$ to $198 \mathrm{~cm}$ due to ridging. As stated before, the ice chart of 25 February correctly indicated the small floe sizes (20$100 \mathrm{~m}$ ) but did not indicate any ice thicker than medium firstyear ice $(70-120 \mathrm{~cm})$ nor capture any of the ice volume in the rubble fields. After further ice deformation over the next 4 weeks, no peak of the original $30-40 \mathrm{~cm}$ ice is recognizable. The histogram has no distinguishable peaks and has a mean ice thickness of $2.8 \mathrm{~m}$, similar to the ice around beacon 26370 . This is a large value, as thermodynamically

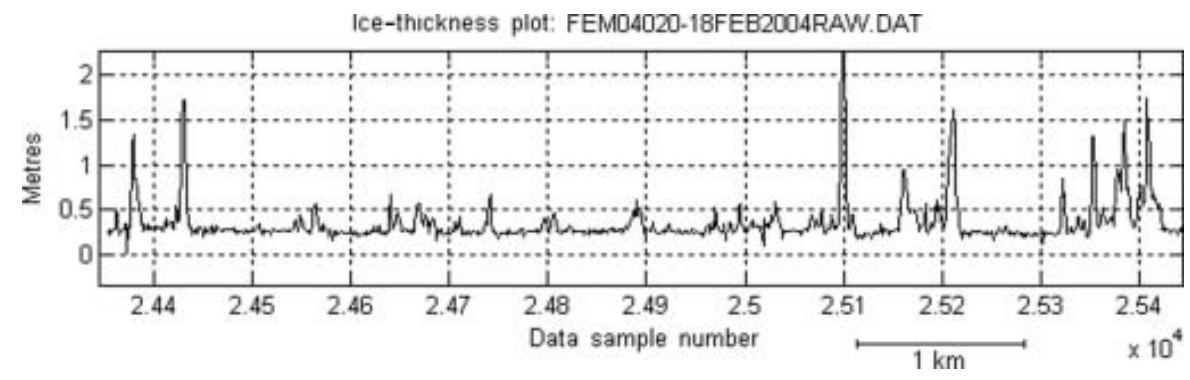

Fig. 8. Ice-thickness line profile from 18 February 2004 of a $7 \mathrm{~km}$ east-west line section across the grey ice and small ridged floe on which beacon 26386 was deployed. 

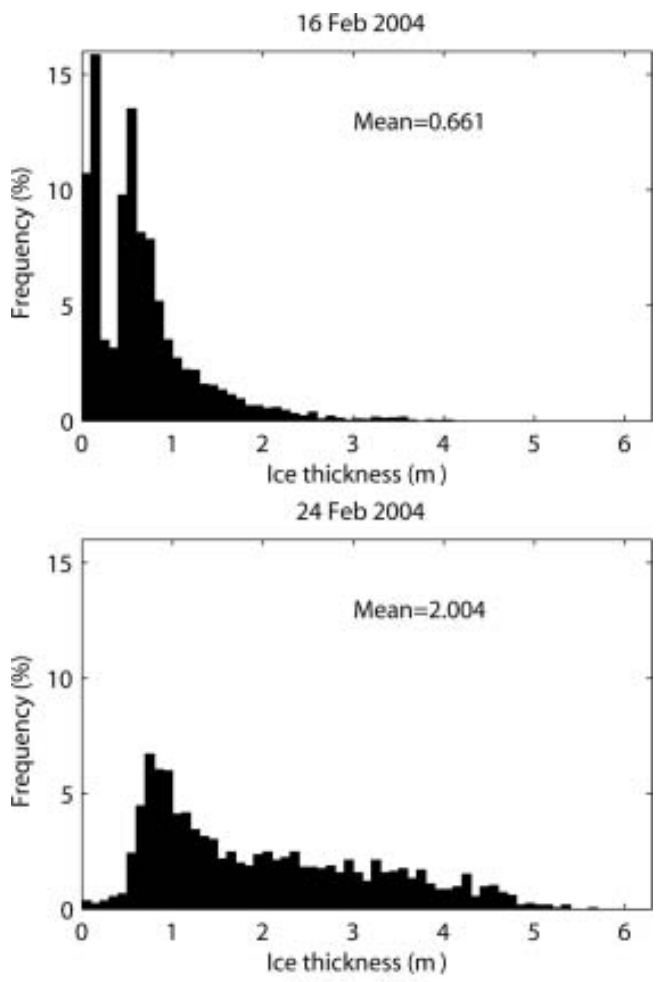

23 Mar 2004

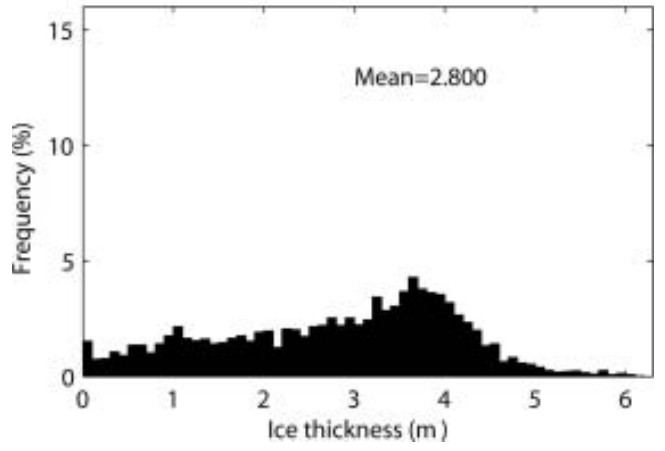

Fig. 9. Ice-thickness histograms of pack ice around beacon 26370.

undeformed ice only grows to $65 \mathrm{~cm}$ in the southern Gulf of St Lawrence (Canadian Ice Centre, 1992).

\section{CONCLUSION}

Of the five beacons deployed to track pack-ice regions for ice evolution studies, only two survived the deformation process and provided the required location data. Three northeasterly storms passed through the area during the second part of February, pushing the pack ice against the north shore of PEI. As expected, the free ice-drift rate was $2-$ $3 \%$ of the wind speed and drifted $35-40^{\circ}$ to the right of the wind vector. It decreased to $0 \%$ when the pack ice compacted against the shoreline.

Ice deformation by the storms caused major changes in the ice-thickness distributions of the pack ice tracked by the two beacons. Most of the thinner ice was first severely deformed into rubble fields so that mean ice thickness over 6-8 $\mathrm{km}$ line sections around the beacons changed from 0.6 and $0.3 \mathrm{~m}$ before the three storms to 1.9 and $2.0 \mathrm{~m}$ after the storms. The reduction in pack-ice area into rubble fields could account for the increase seen in mean ice thicknesses. Ice charts capture the increase in ice thickness for composite
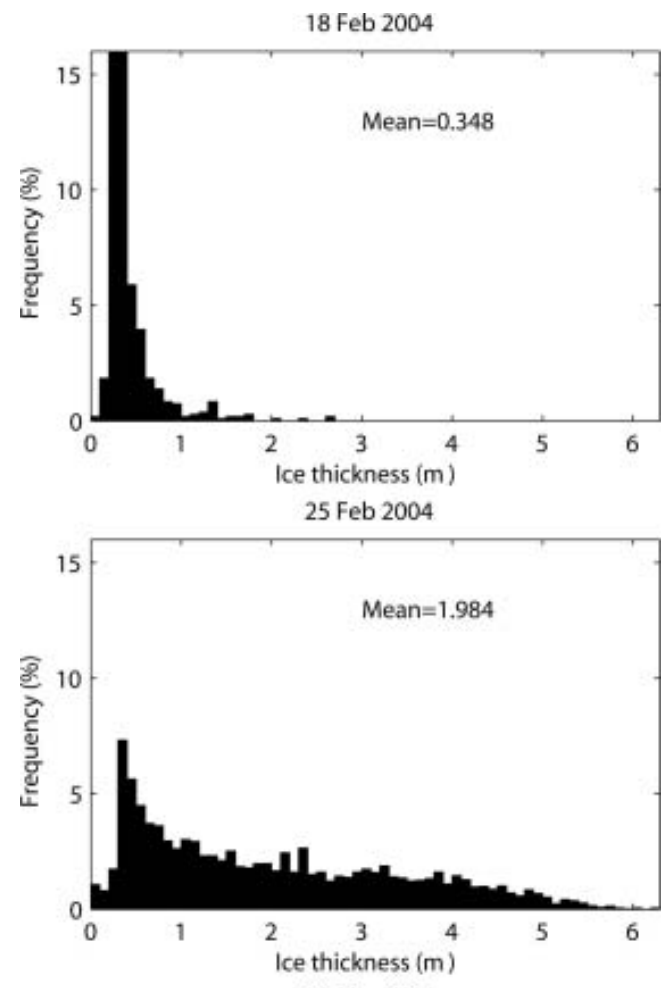

23 Mar 2004

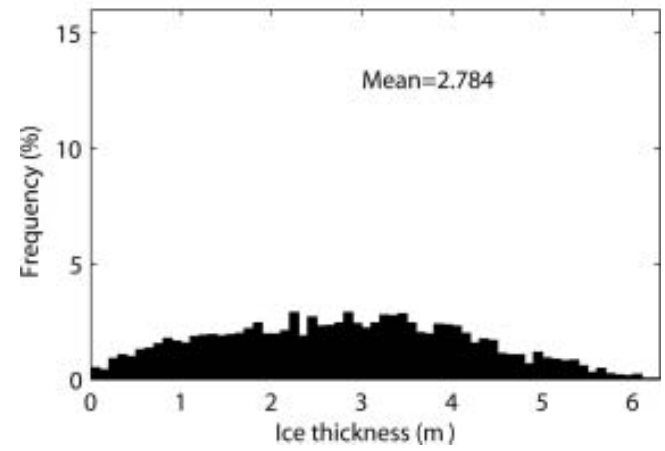

Fig. 10. Ice-thickness histograms of pack ice around beacon 26386 .

ice floes but do not capture the ice volume within the icerubble fields.

The data also showed that as deformation continues, the final histograms do not retain peaks of the original undeformed ice. The two ice-thickness histograms from the southern Gulf of St Lawrence in late winter thus looked very similar, except that the one starting with the thicker ice (area around beacon 26370) appeared to have thicker final icerubble fields. This is in agreement with the results by $\mathrm{H}$. Melling which showed that the thicker the undeformed ice (original building blocks) before ridging, the larger the maximum ice thickness of the ridges formed (Amundrud and others, 2004).

\section{ACKNOWLEDGEMENTS}

We greatly appreciate the support given by the Program of Energy Research and Development (PERD) and the Canadian and European Space Agencies. We also thank personnel from the Canadian Coast Guard based at Charlottetown, and S. Holladay from Geosensors Inc. of Toronto, Canada, for assistance during the field survey. C. Haas and colleagues' review comments and discussions during the Sea Ice Symposium were greatly appreciated. 


\section{REFERENCES}

Amundrud, T.L., H. Melling and R.G. Ingram. 2004. Geometrical constraints on the evolution of ridged sea ice. J. Geophys. Res., 109(C6), C06005. (10.1029/2003JC002251.)

Canadian Ice Centre. 1992. Ice thickness climatology 1961-1990 normals. Ottawa, Ont., Ice Climatology Service.

Haas, C., S. Hendriks and M. Doble. 2006. Comparison of the seaice thickness distribution in the Lincoln Sea and adjacent Arctic Ocean in 2004 and 2005. Ann. Glaciol., 44 (see paper in this volume).

Hibler, W.D. 1972. Removal of aircraft altitude variation from laser profiles of the Arctic pack. J. Geophys. Res., 77(36), 7190-7195.

Kovacs, A., J.S. Holladay and C.J. Bergeron, Jr. 1995. Footprint/ altitude ratio for helicopter electromagnetic sounding of sea-ice thickness: comparison of theoretical and field estimates. Geophysics, 60(2), 374-380.

Melling, H. and D.A. Riedel. 2004. Draft and movement of pack ice in the Beaufort Sea: a time-series presentation April 1990August 1999. Can. Tech. Rep. Hydrogr. Ocean Sci. 238.

Melling, H., D.A. Riedel and Z. Gedalof. 2005. Trends in the draft and extent of seasonal pack ice, Canadian Beaufort Sea. Geophys. Res. Lett., 32(24), L24501. (10.1029/2005GL024483.)
Peterson, I.K., S.J. Prinsenberg and A. Maillet. 1998. 1997 pack ice properties in Northumberland Strait. In Proceedings of the 8th International Offshore and Polar Engineering Conference. Vol. 2. Cupertino, CA, International Society of Offshore and Polar Engineers, 513-518.

Peterson, I.K., S.J. Prinsenberg and J.S. Holladay. 2003. Sea-ice thickness measurement: recent experiments using helicopter-borne electromagnetic systems. Recent Res. Devel. Geophys., 5, 1-20. Prinsenberg, S.J., S. Holladay and J. Lee. 2002. Measuring ice thickness with EISFlow ${ }^{\mathrm{TM}}$, a fixed-mounted helicopter electromagnetic-laser system. In Proceedings of the 12th International Offshore and Polar Engineering Conference. Vol. 1. Cupertino, CA, International Society of Offshore and Polar Engineers, 737-740.

Richter-Menge, J.A., D.K. Perovich, B.C. Elder, K. Claffey, I. Rigor and M. Ortmeyer. 2006. Ice mass-balance buoys: a tool for measuring and attributing changes in the thickness of the Arctic sea ice cover. Ann. Glaciol., 44 (see paper in this volume).

Wadhams, P. and N.R. Davis. 2000. Further evidence of sea ice thinning in the Arctic Ocean. Geophys. Res. Lett., 27(24), 3973-3976.

Yu, Y., G.A. Maykut and D.A. Rothrock. 2004. Changes in the thickness distribution of Arctic sea ice between 1958-1970 and 1993-1997. J. Geophys. Res., 109(C8), C08004. (10.1029/ 2003JC001982.) 